\title{
Perancangan Monitoring Robot Kiper Melalui Acces Point Sebagai Media Kendali Robot
}

\author{
Ey Afif Habibie ${ }^{1}$, Mukhlidi Muskhir² \\ 1,2 Jurusan Teknik Elektro, Fakultas Teknik, Universitas Negeri padang \\ Jl. Prof. Dr. Hamka Air Tawar Padang, Sumatera Barat, 25132, Indonesia \\ Afifhabib72@gmail.com ${ }^{1}$,muskhir@ft.unp.ac,id ${ }^{2}$
}

\begin{abstract}
- as time goes by, the development of technology is getting more advanced, previously robot control was done manually which made robot movement inflexible and irrelevant. This study aims to answer these problems by creating an automatic movement control system. The base station application is used to connect the robot to the computer control or it is called the Referee Box. The Referee Box computer serves as a server for the base station and the base station as a server for the robot, where data transmission is carried out end to end, where data transmission is implemented directly to the robot. In this study, testing the sending of information from the Referee Box to the Base Station using a LAN cable, where data transmission from the Base Station to the robot is carried out wirelessly and orders will be carried out in the form of a robot movement. The test results are in the form of an application that can be used as a communication medium and robot monitoring which is carried out in real time.
\end{abstract}

Keywords-Monitoring, Basestaton,refereebox.robot,wireless.

\begin{abstract}
Abstrak - seiring berjalan waktu perkembangan teknologi semakin maju yang sebelumnya pengendalian robot dilakukan secara manual yang membuat membuat pergerakan robot menjadi tidak fleksibel dan tidak relevan lagi. Penelitian ini bertujuan untuk menjawab permasalahan tersebut.dengan cara membuat suatu sistem kontrol pergerakan otomatis. Base station aplikasi yang berguna menghubungkan robot dengan komputer pengendali atau disebut dengan Referee Box. Komputer Referee Box sebagai server bagi base station dan base station sebagai server bagi robot.yang mana pengiriman data dilakukan secara end to end.yang mana pengiriman data di implementasikan secara langsung ke robot. Pada penelitian ini dilakukan pengujian pengiriman informasi dari Referee Box ke Base Station menggunakan kabel LAN, dimana pengiriman data dari Base Station ke robot dilakukan secara wireless dan perintah akan dilakukan dalam bentuk pergerakan robot. Hasil pengujian berupa aplikasi yang dapat digunakan sebagai media komunikasi dan monitoring robot yang dilakukan secara realtime.
\end{abstract}

Kata kunci-Monitoring, Basestaton,refereebox.robot,wireless.

\section{Pendahuluan}

Robotika saat ini telah menjadi bagian dari kehidupan. Robotika telah menjadi salah satu perkembangan teknologi bukan hanya di negara-negara maju melainkan sudah menyebar di negara-negara berkembang. Beberapa negera maju terus berupaya untuk terus mengembangkan penelitian di dunia robotika.[1] Kontes Robot Indonesia (KRI) merupakan salah satu bukti perkembangan robotika dalam bidang pendidikan yang diadakan oleh Kementrian Riset Teknologi dan Pendidikan Tinggi (KEMENRISTEKDIKTI) yang bertujuan untuk menumbuhkan, meningkatkan kreativitas, dan kepekaan mahasiswa perguruan tinggi dalam mengembangkan teknologi robotika.[2] Kontes Robot Sepak Bola Beroda Indonesia (KRSBI Beroda) merupakan salah satu kategori dalam Kontes Robot Indonesia (KRI) yang diselengarakan oleh Kementrian Riset Teknologi dan Pendidikan Tinggi (KEMENRISTEKDIKTI).[3] Kontes Robot Sepak Bola Beroda Indonesia menggunakan banyak teknologi dalam menjalankan pertandingan.[4] Pada saat pertandingan, robot akan dikontrol dan diperintah berdasarkan instruksi wasit melalui perangkat lunak yang disebut Referee Box. Masing-masing robot diharuskan dapat menerjemahkan aksi berdasarkan instruksi yang diberikan, seperti Free Kick, Goal Kick, Kick Off dan sebagainya.[5] Oleh karena itu diperlukan adanya sebuah sistem komunikasi yang menjembatani komunikasi antara Referee Box dengan robot sehingga robot dapat menerima dan menerjemahkan instruksi yang diberikan dari Referee Box. Untuk membuat robot dapat menerima perintah dari Referee Box, dibutuhkan bantuan sebuah aplikasi Base Station.[6] Selain itu, pembuatan aplikasi Base Station membuat robot dapat menjadi lebih fleksibel untuk berpindah tempat. Dengan dibuatnya aplikasi Base Station ini diharapkan dapat membuat fungsi dari Referee Box sebagai wasit menjadi lebih efektif serta dapat meminimalisir campur tangan manusia dengan robot secara langsung.[7]

\section{Refree Box}

Refree box (disingkat Refbox) adalah sebuah perangkat komputer yang berisi aplikasi game controller yang digunakan dalam kontes robot Indonesia yang berfungsi sebagai pengatur jalannya pertandingan robot 
sepak bola beroda. Refbox memberikan perintah berupa dimulainya pertandingan, akhir pertandingan, pelanggaran dan tendangan bebas, dan lain-lain. Antarmuka pengguna tekstual dan grafis memungkinkan untuk instruksi dan pengawasan oleh manusia. Hal ini diperlukan secara khusus dalam situasi yang tidak terduga (misal Manusia harus menghentikan permainan karena sesuatu hal). Refbox juga mencatat setiap pesan yang dikirim atau yang diterima.[8]

\section{Base Sation}

Base Station merupakan sebuah perangkat lunak yang dirancang sedemikian rupa untuk mengontrol, mengkoordinasi serta memonitoring kondisi robot selama bertanding. Base Station diharuskan dapat bekerja secara otomatis tanpa adanya interupsi selama pertandingan, oleh karena itu dibutuhkan koneksi yang handal serta kemampuan dalam pemrosesan data yang diterima secara cepat. [9]

\section{Access Point}

Access point merupakan sebuah perangkat dalam jaringan komputer yang dapat menciptakan jaringan lokal nirkabel atau WLAN (Wireless Local Area Network). Access point akan dihubungkan dengan router atau hub atau switch melalui kabel Ethernet dan memancarkan sinyal wifi di area tertentu. Untuk dapat terhubung dengan jaringan lokal yang telah dikonfigurasikan tersebut, perangkat harus melalui access point. Access point terdiri dari antenna dan transceiver, dan bertindak sebagai pusat pemancar dan penerima sinyal dari dan untuk client-server. Access point tidak dapat mengatur aliran data seperti router, access point hanya akan menyambungkan atau tidak menyambungkan suatu perangkat yang mencoba untuk terhubung dengan jaringan, berdasarkan benar atau tidaknya password yang diberikan pengguna perangkat[10]

\section{Metode}

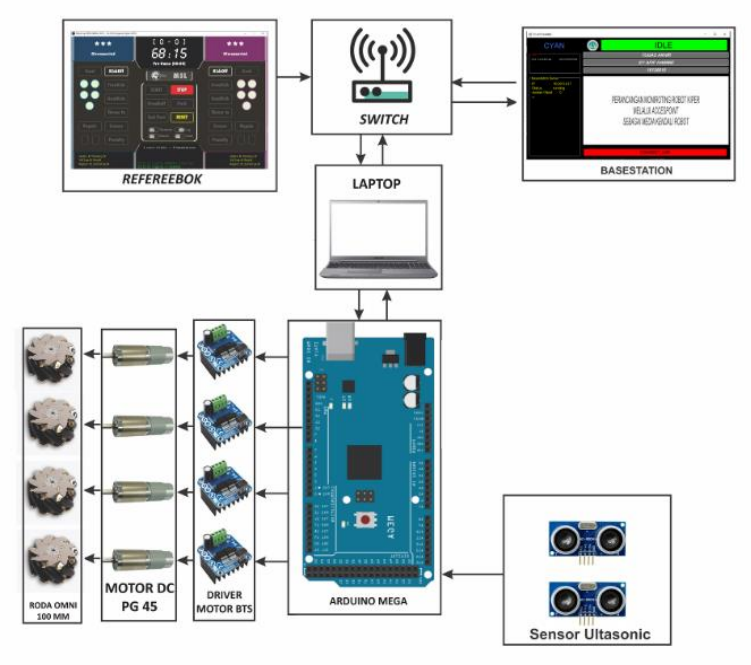

Gambar 1 Perancangan kerja sistem
Pada tahap ini makan akan dilakukan penggambaran dan metoda peracangan sistem pada alat, dengan lebih jelas cara kerja sistem dapat dilihat pada gambar 1 perancangan kerja sistem. Secara garis besar dapat dilihat bahwa terdapat tiga komponen penting yang ada pada sistem yaitu input, process, dan output. Referee Box akan digunakan sebagai input pada sistem yang bertugas mengirimkan informasi kepada Base Station melalui media transmisi data kabel Ethernet (LAN). Base Station sebagai bagian dari process selanjutnya akan bertugas untuk mengolah informasi yang diterima dari Referee Box melalui kabel Ethernet (LAN), dimana informasi tersebut akan diteruskan secara wireless kepada robot

Tabel I. Alat Dan Bahan

\begin{tabular}{|c|c|c|}
\hline No & Alat Dan Bahan & Nama \\
\hline 1 & $\begin{array}{l}\text { Perangkat } \\
\text { keras(hardware) }\end{array}$ & $\begin{array}{ll} & \text { Mikrokontroler Arduino } \\
& \text { Mega 2560 } \\
\text { - } & \text { Router TP-LINK } \\
\text { - } & \text { Kabel Ethernet (LAN) } \\
\text { - } & 3 \text { Laptop } \\
& \text { Robot kipper beroda } \\
\end{array}$ \\
\hline 2 & $\begin{array}{l}\text { Perangkat } \\
\text { lunak(Software) }\end{array}$ & $\begin{array}{ll}\text { - } & \text { Referee Box } \\
\text { - } & \text { Gui Base station } \\
\text { - } & \text { Python } \\
\text { - } & \text { Arduino IDE }\end{array}$ \\
\hline
\end{tabular}

\section{Blok Diagram}

Secara umum blok diagram perancangan monitoring robot kipper melalui accespoint sebagai media kendali robot dijelaskan pada gambar 2 .

Berdasarkan blok diagram keseluruhan sistem di gambar 2, fungsi dari masing-masing blok diagram sebagai berikut:

1. Refereebok merupakan perangkat lunak yang berfungsi untuk mengatur dan mengendalikan jalannya pertandingan

Base station merupakan sebuah perangkat lunak yang dirancang sedemikian rupa untuk mengontrol, mengkoordinasi serta memonitroing kondisi robot selam bertanding

2. Accespoint penghubung robot dengan base station melalui jaringan wifi sebagai media perantara

3. Laptop difukuskan untuk megolah perintah dari refereebok yang terkoneksi dengan basestation

4. Mikrokontroler Atmega 2560 sebagai mikrokontroler yang lebih difukuska untuk megolah/megontrok perangkat keras yang ada pada robot

5. Sensor ultrasonic berfungsi sebagai sensor jarak yang mana digunakan sebagai pendeteksi posisi robot dengan gawang

6. Driver motor berfungsi sebagai penerjemah data dari Arduino sehingga dapat melakukan pengaturan 
arah,pengereman,dan kecepatan motor yang merupakan penggerak utama

7. Motor DC berfungsi sebgai komponen perangkat keras penggerak utama pada robot

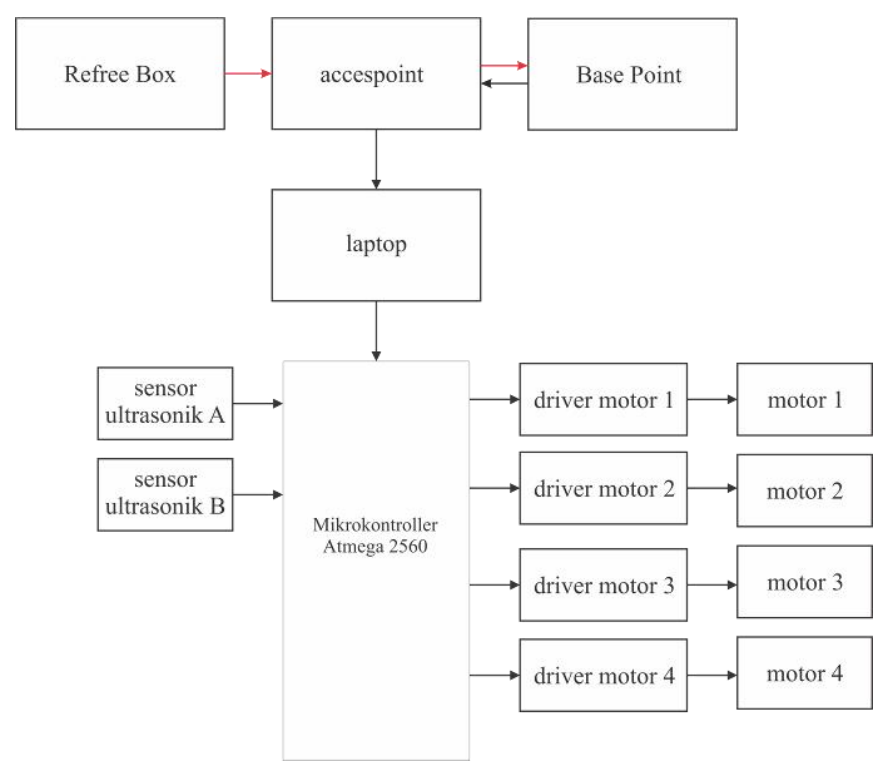

Gambar 2. Blok diagram keseluruhan

\section{Flowchart}

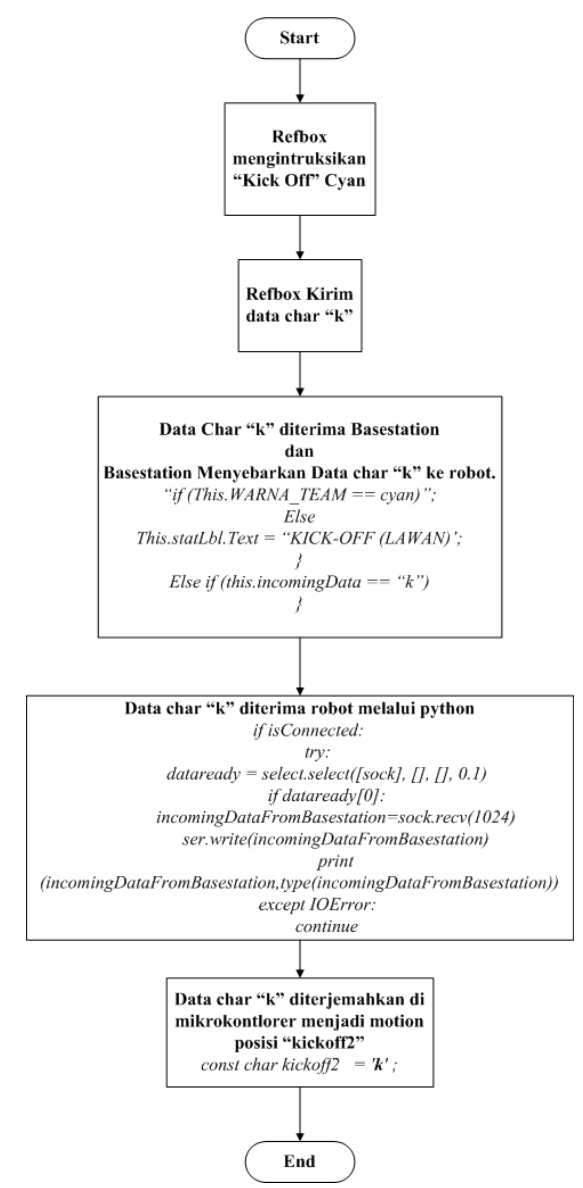

Gambar 3. Flowchart proses pengiriman data
Prinsip kerja pada monitoring robot kipper melalui accespoint sebagai media kendali robot dijelaskan melalui suatu gambar atau bagan urutan perancangan program. Seperti yang di tunjukan pada gambar 3 .

Pada gambar 3 dijelaskan flowchart proses pengiriman data yang mana dimulai dari refbox mengirim data kickoff cyan yang berbentuk karakter "k" dan diterima oleh basestation yang diteruskan ke robot melalui python dan robot menirima data byte yang langsung diolah sesuai keadaan yang dibuat.

\section{Perancangan Hardware}

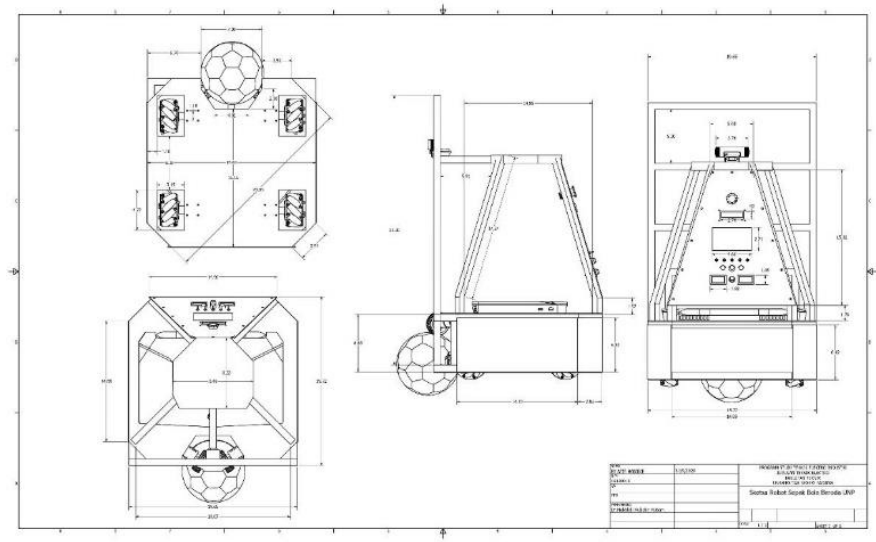

Gambar 4. Rancangan bentuk fisik alat

Perancangan hardware merupakan suatu tahapan proses Yang penting dalam pembuatan suatu perangkat keras. Dengan adanya perancangan hardware pada tugas akhir ini maka sistem alat tersebut dapat diuji bahwa alat ini dapat bekerja dengan sangat baik sesuai dengan perancangannya. Bentuk rancangan fisik alat tersebut dapat dilihat pada gambar 4 .

\section{Perancangan Software}

Dalam melakukan kegiatan pengolahan data diperlukan perangkat lunak yang mampu dapat memproses data dari sensor sebagai input, sehingga menghasilkan suatu output sebagai hasil akhir dari rancangan alat yang dibuat seperti yang dapat dilihat dari gambar 5 perancangan software.

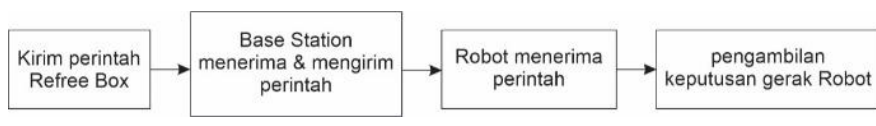

Gambar 5. Blok diagram software monitoring

\section{HASIL DAN PEMBAHASAN}

Proses pengujian dilakukan untuk memastikan kebenaran program yang telah diimplementasikan, sehingga pengguna dapat menggunakan program ini 
dengan baik sesuai fungsi program ini dibuat. Sesuai dengan tujuan dari penelitian ini yaitu menghasilkan sistem yang dapat mengkomunikasikan RefBox dengan Robot melalui Base Station, maka dalam penilitian ini RefBox yang digunakan adalah RefBox resmi dari Robocup MSL, untuk Base Station menggunakan laptop, dan untuk robot juga menggunakan sebuah laptop.

\section{Refreebox}

RefBox atau Referee Box adalah perangkat lunak yang digunakan untuk mengatur dan mengontrol kompetisi. Refbox dioperasikan olhe wasit. RefBox mengirimkan perintah ke basestation, dan kemudian meneruskannya ke robot. Informasi instruksi termasuk permainan mulai MULAI, permainan berhenti BERHENTI, instruksi kick-off, tendangan bebas, DropBall dan status permainan lainnya. Betuk dari refbox yang telah terkoneksi dengan basestation dapat dilihat di gambar 6

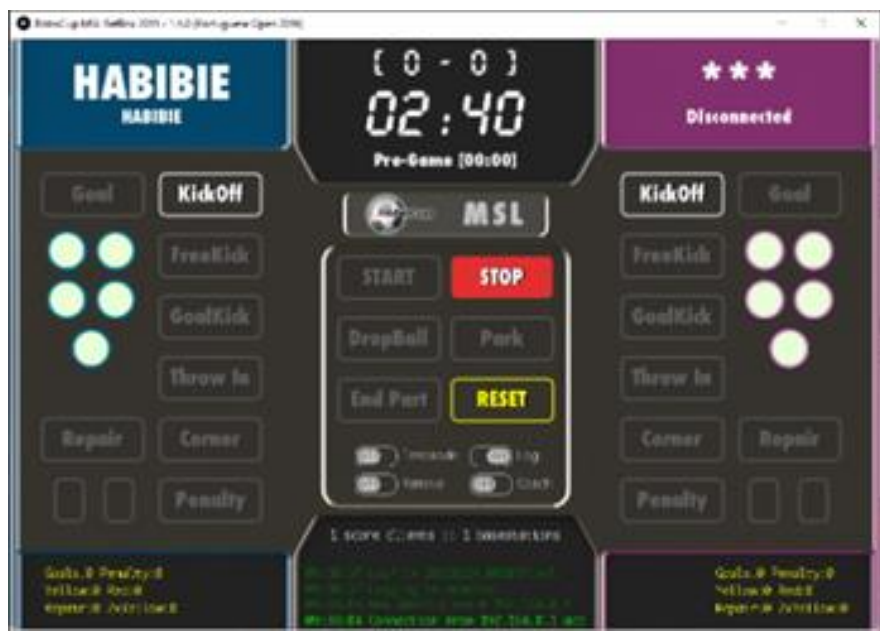

Gambar 6. Refreebox

\section{Base Station}

Base Station adalah komputer, notebook, atau laptop yang menjalankan software yang digunakan untuk memantau dan mengatur kerja robot secara otomatis berdasarkan instruksi yang diterima dari RefBox. BaseStation melakukan koordinasi aktivitas setiap robotnya dalam pertandingan. Selama pertandingan sedang berjalan, anggota tim peserta tidak diizinkan untuk mengoperasikan Base Stationnya. Base Station menggunakan kabel Ethernet Switch untuk melakukan koneksi dengan RefBox. BaseStation memanggil alamat IP (IP Address) RefBox untuk melakukan koneksi melalui Port 28097 (default). Alamat IP Komputer yang menjalankan RefBox akan diumumkan pada saat pertandingan. Cara koneksi antara Base Station dengan robot yakni setiap robot memiliki alamat IP (IP address). Base Station dapat terhubung dengan robot secara wireless melalui access point yang khusus disediakan panitia dalam pertandingan.

Pada pengujian ini dilihat saat Basestation berjalan dan terkoneksi dengan Refrebox, dan juga memonitorong pergerakan robot kiper yang dilakukan saat pertandingan berlangsung. Bentuk basestation saat dalam kondisi terkoneksi cyan dapat dilihat pada tabel 2.

Tabel II. Pengujian Basestation

\begin{tabular}{|c|c|c|}
\hline No & Gambar & Kondisi \\
\hline 1 & $\begin{array}{l}\text { pilih warna TEAM } \\
\text { ? } \begin{array}{l}\text { warna team?? } \\
\text { klik yes kalau CYAN } \\
\text { klik no kalau MAGENTA }\end{array} \\
\text { Yes } \\
\end{array}$ & $\begin{array}{l}\text { BaseStation pilih } \\
\text { team cyan atau } \\
\text { magenta }\end{array}$ \\
\hline 2 & 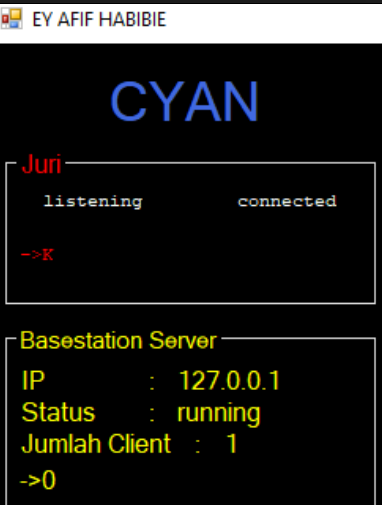 & $\begin{array}{l}\text { Basestation dalam } \\
\text { keadaan terkoneksi } \\
\text { team cyan }\end{array}$ \\
\hline 3 & 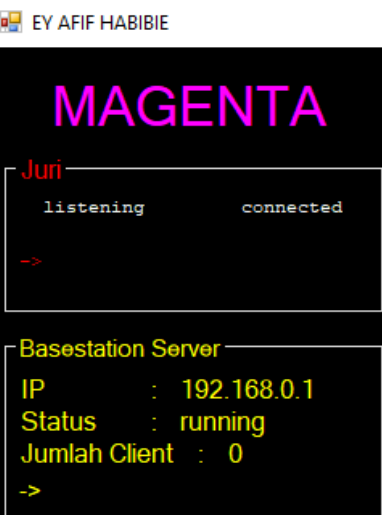 & $\begin{array}{c}\text { Basestation dalam } \\
\text { keadaan terkoneksi } \\
\text { team Magenta }\end{array}$ \\
\hline 4 & CYAN KICK.OFF (LAWAN) & $\begin{array}{c}\text { Basestation } \\
\text { menerima perintah } \\
\text { kick off lawan }\end{array}$ \\
\hline 5 & CYAN KICK.OFF (KITA) & $\begin{array}{c}\text { Basestation } \\
\text { menerima perintah } \\
\text { kick off kita }\end{array}$ \\
\hline
\end{tabular}

\section{Pengujian di robot}

Pada pengujian jenis data ini, hanya jenis data byte yang berhasil menerima perintah dari RefBox. Karena data yang diterima berupa byte, maka agar pengguna program dapat mengetahui data apa yang diterima, data byte yang diterima diterjemahkan ke dalam bahasa ASCII. Data "75" yang diterima setelah diterjemahkan ke dalam bahasa ASCII berhasil dirubah menjadi karakter "K" dan karakter lainya, dimana karakter tersebut sesuai dengan data yang dikirim RefBox seperti yang dapat dilihat dari tabel 3. 
Tabel III. Pengujian di robot

\begin{tabular}{|c|c|c|}
\hline No & Gambar & Kondisi \\
\hline 1 & $\begin{array}{l}=====\text { RESTART: D: } \backslash \text { PROGRAM TA EY AFIF HP } \\
\text {---------CONNECTED TO BASESTATION----- }\end{array}$ & $\begin{array}{c}\text { Robot terkoneksi } \\
\text { dengan } \\
\text { Basestation }\end{array}$ \\
\hline 2 & 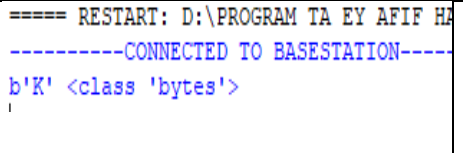 & $\begin{array}{c}\text { Robot Terima } \\
\text { Perintah kick off } \\
\text { kita "K" }\end{array}$ \\
\hline 3 & $\begin{array}{l}====\text { RESTART: D: } \backslash \text { PROGRAM TA EY AFIF H } \\
--------C O N N E C T E D \text { TO BASESTATION---- } \\
b^{\prime} \mathrm{k}^{\prime}\langle\text { class 'bytes'> }\end{array}$ & $\begin{array}{l}\text { Robot terima } \\
\text { perintah Kick off } \\
\text { lawan "k" }\end{array}$ \\
\hline
\end{tabular}

Dan juga dapat dilihat di table 3 saat kondisi awal mula dengan perintah yang telah dikirim.

Tabel IV. Kondisi robot

\begin{tabular}{|c|c|c|c|}
\hline No & Kondisi & Perintah & $\begin{array}{c}\text { Satate program } \\
\text { Arduino }\end{array}$ \\
\hline 1 & $\begin{array}{c}\text { Awal mula } \\
\text { pertandingan }\end{array}$ & $\begin{array}{c}\text { Kick Off } \\
\text { cyan ('K') }\end{array}$ & Suruah_reading \\
\hline 2 & $\begin{array}{c}\text { Awal mula } \\
\text { pertandingan }\end{array}$ & $\begin{array}{c}\text { Kick Off } \\
\text { cyan ('K') }\end{array}$ & Suruah_reading \\
\hline 3 & $\begin{array}{c}\text { Saat } \\
\text { pertandingan }\end{array}$ & Stop("S") & Suruah_diam \\
\hline
\end{tabular}

Tabel V. Keberhasilan uji pengiriam data RefreeBox

\begin{tabular}{|c|c|c|c|c|}
\hline No & $\begin{array}{c}\text { Jenis } \\
\text { Perintah }\end{array}$ & $\begin{array}{c}\text { Data } \\
\text { Dikirim } \\
\text { Referee } \\
\text { Box }\end{array}$ & $\begin{array}{c}\text { Data } \\
\text { Diterima } \\
\text { Base } \\
\text { station }\end{array}$ & Keterangan \\
\hline 1 & $\begin{array}{c}\text { Kick Off } \\
\text { cyan }\end{array}$ & $\mathrm{K}$ & $\mathrm{K}$ & Berhasil \\
\hline 2 & $\begin{array}{c}\text { Kick Off } \\
\text { magenta }\end{array}$ & $\mathrm{K}$ & $\mathrm{K}$ & Berhasil \\
\hline 3 & Start & $\mathrm{S}$ & $\mathrm{S}$ & Berhasil \\
\hline 4 & Stop & $\mathrm{S}$ & $\mathrm{S}$ & Berhasil \\
\hline
\end{tabular}

Tabel VI. Keberhasilan uji pengiriman data Basestation

\begin{tabular}{|c|c|c|c|c|}
\hline No & $\begin{array}{c}\text { Data } \\
\text { Jang } \\
\text { Penis } \\
\text { diterima } \\
\text { dan } \\
\text { dikirim } \\
\text { Base } \\
\text { Station }\end{array}$ & $\begin{array}{c}\text { Data } \\
\text { diterima } \\
\text { Robot }\end{array}$ & Keterangan \\
\hline 1 & $\begin{array}{c}\text { Kick Off } \\
\text { cyan }\end{array}$ & $\mathrm{K}$ & kickoff1 & Berhasil \\
\hline
\end{tabular}

\begin{tabular}{|c|c|c|c|c|}
\hline 2 & $\begin{array}{c}\text { Kick Off } \\
\text { magenta }\end{array}$ & K & Kickoff2 & Berhasil \\
\hline 3 & Start & S & Mulai & Berhasil \\
\hline 4 & Stop & S & Stop & Berhasil \\
\hline
\end{tabular}

Table VII. Keberhasilan uji data di robot

\begin{tabular}{|c|c|c|c|}
\hline No & Jenis Perintah & Aksi Robot & Keterangan \\
\hline 1 & Kic Off kcyan & Suruah_reading & Berhasil \\
\hline 2 & $\begin{array}{c}\text { Kick Off } \\
\text { magenta }\end{array}$ & Suruah_reading & Berhasil \\
\hline 3 & Start & Suruah_reading & Berhasil \\
\hline 4 & Stop & Suruah_stop & Berhasil \\
\hline
\end{tabular}

\section{PENUTUP}

Sesuai dengan hasil pengujian, dapat ditarik kesimpulan bahwa data yang dapat dikirim dari RefBox ke Base Station hanya berupa data byte, yang nantinya data byte tersebut mewakili satu karakter dalam bahasa ASCII, sehingga pada akhirnya akan dikirim ke MiniPC robot berupa satu karakter khusus dan diterjemahkan di sistem minimum mikrokontroler robot, dan berubah menjadi respon gerak otomatis robot.

Beradasarkan perancangan dan pembuatan sebuah sistem perancangan monitirong robot kipper melalui accespoint sebagai media kendali robot, masih banyak terdapar kekurangan pada sistem, Untuk itu penulis memberikan saran dan masukan agar kedapannya alat ini bias lebih lagi. Berikut saran dan tambahan dari penulis yang dapat dikembangan :

1. GUI basestation masih perlu pengembangan, agar fitur dan kegunaan bisa lebih banyak.

2. Pengembangan gui di robot belum ada, sehingga komunikasi basestation belum terpakai secara maksimal

3. Perkembangan dalam lomba krsbi setiap tahun terus bertambah, harapan penulis agar kita bisa terus mengikuti proses perkembangan yang ada.

\section{REFERENSI}

[1] R. Risfendra, A. Asfinaldi, H. Habibullah, and J. Julisardi, "Sistem Pergerakan Robot Kiper Beroda Menggunakan Metode Wall Follower Berbasis Image Processing," Elkha, vol. 12, no. 1, p. 1, 2020, doi: 10.26418/elkha.v12i1.35245. 
[2] Panitia Pusat Kontes Robot Indonesia, "Buku Panduan Kontes Robot Sepakbola Indonesia 2019," p. 3, 2018, [Online]. Available: http://kontesrobotindonesia.id/data/2018/Pandu anKRSBIBeroda2018.pdf.

[3] Ristekdikti, "Buku Panduan Kontes Robot Sepakbola Indonesia Beroda (KRSBI Beroda)," Direktorat Kemahasiswaan Direktorat Jenderal Pembelajaran dan Kemahasiswaan Kementeri. Riset, Teknol. dan Pendidik. Tinggi Republik Indones., pp. 15-46, 2018.

[4] I. Ardiyanto, R. T. Hartanto, F. A. Rahman, Y. A. D. D, and O. F. Suryani, "Development of Middle-Sized Mobile Robot FUKURO for Robot Soccer Competition," no. July 2020, 2018.

[5] B. Station and M. Tcp, "Design of Wheeled Football Robot Coordination System at Base Station Using TCP / IP Perancangan Sistem Koordinasi Robot Sepak Bola Beroda Pada," vol. 4, no. 1, 2020.

[6] Fitri, K. R. R, A. Rahmansyah, and W. Darwin, "Penggunaan Bahasa Pemrograman Python Sebagai Pusat Kendali Pada Robot 10-D," 5th Indones. Symp. Robot. Syst. Control, pp. 23-26, 2017.

[7] F. Tjoanapessy et al., "Aplikasi Base Station Untuk Robot Sepak Bola Beroda,” vol. 14, no. 3, pp. 285290, 2019.

[8] P. P. Nasional and R. Indonesia, "Pelaksanaan Kontes Robot Indonesia Daring," 2020.

[9] K. Nasikhin, "Pemetaan Posisi Robot Sepak Bola
Beroda Menggunakan Metode Gyrodometry Untuk Memprediksi Sudut Tendangan Bola Terhadap Gawang Lawan Dengan Perhitungan Trigonomteri," 2019.

[10] T. Ardhiansyah, I. Syarifuddin, M. R. Naufal, Y. Pramono, and 0. T. Hartatik, "Pergerakan Otomatis Robot Sepak Bola Beroda Melalui Komunikasi dengan Referee Box Menggunakan Base Station," 5th Indones. Syposium Robot. Syst. Control, no. June 2018, pp. 82-86, 2017.

\section{Biodata Penulis}

Ey Afif Habibie, Lahir di padang ganting, 06 Desember 1997. Menyelesaikan studi DIV Teknik Elektro Industri pada Jurusan Teknik Elektro Fakultas Teknik Universitas Negeri Padang.

Mukhlidi Muskhir, lahir di Padang 8 september 1973. Mengikuti pendidikan S1 Pendidiakan teknik eletro IKIP Padang pada tahun 1993 hingga 1998, dan melanjutkan pendidikan S2 Ilmu komputer Universitas Gajah Mada pada tahun 2000 hingga 2003. Dan melanjutkan pendidikan S3 PTK Universitas Negeri Yogyakarta pada tahun 2010 hingga 2017. Sejak tahun 2008 menjadi dosen tetap di jurusan Teknik Elektro Fakultas Teknik Universitas Negeri Padang hingga sekarang. 